Concurso

\section{Alameda, Lira y Quito Santiago, Chile}

FECHA 2001

NÜMERO DE PROYECTOS RECIBIDOS 8

DIRECCIŌN DEL CONCURSO LUIS EDUARDO BRESCIAN

IURADO PEDRO BANNEN (PRESIDENTE), MIGUEL BAUDIZZONE, ALBERTO DITTBORN, HANS MÜHR, ALFONSO SWET, ALEAANDRO GUTÉPPEZ (REPREEENTANTE DE LOS CONCURSANTES)

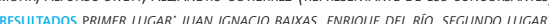

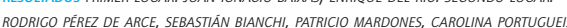

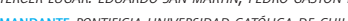
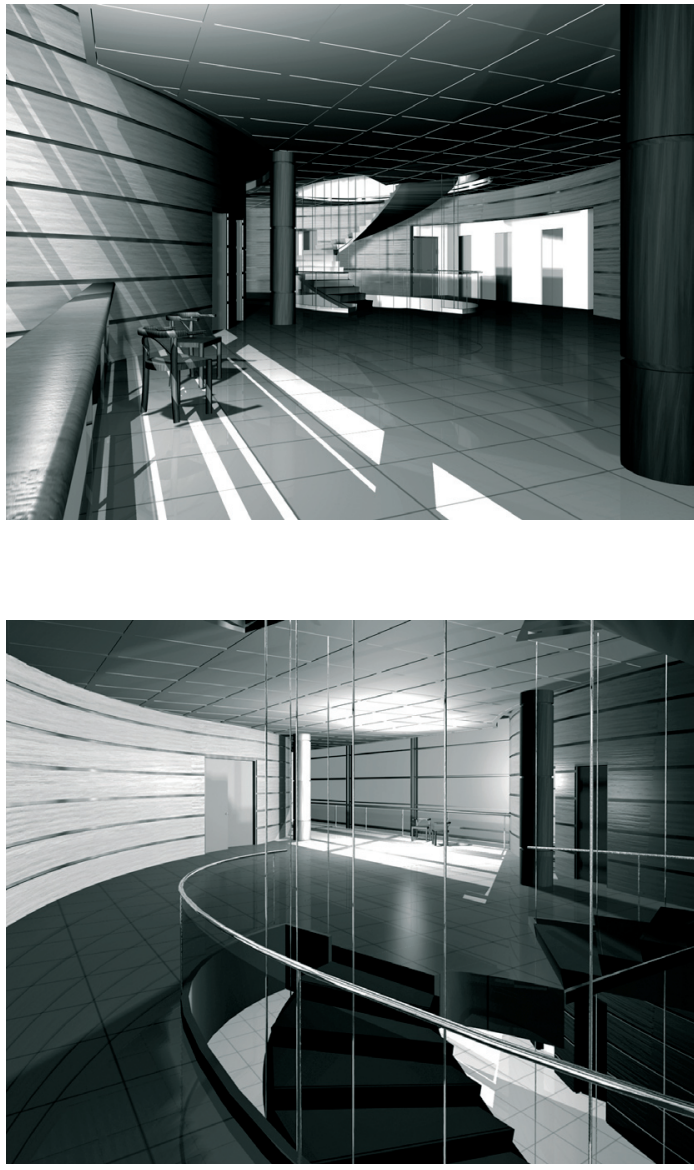

El nuevo Plan Director busca consolidar un territorio al interior de la irregular manzana resultante entre las calles Alameda, Lira y Quito. A la manera de un gran patio urbano, los nuevos edificios contribuyen a consolidar la presencia de la Universidad en el centro de la ciudad.

PRIMER PREMIO

Juan Ignacio Baixas Director, Escuela de Arquitectura, Pontificia Universidad Católica de Chile Enrique del Río Profesor, Escuela de Arquitectura, Pontificia Universidad Católica de Chile the city.
Frente al encargo de crear un Plan Director en tres etapas para una nueva ala del edificio que alberga la Casa Central de nuestra universidad, se propone un conjunto arquitectónico que abra la universidad a las distintas escalas hoy presentes en la ciudad, de las cuales queremos rescatar dos que consideramos importantes: la de los vacíos-plazas y la de los grandes hitos verticales. Creemos que el conjunto debe ser pensado como un anteproyecto de arquitectura y desde allí, abstraído a un Plan Director. Nuestra proposición genera tres elementos arquitectónicos:

Primer elemento: patio urbano / Se propone un cuarto patio del campus prolongando su frente a la Av. Alameda. Este es un patio abierto a la ciudad, que se lee como un vacío urbano. El patio se genera en una prolongación del nivel del piso noble de la universidad hacia el poniente, el cual, gracias a la pendiente natural de Santiago, pasa a cuatro metros por sobre la calle Lira y permite una continuidad peatonal interior. La diferencia de altura entre el cuarto patio y la Alameda genera una amplia escalinata que representa una nueva actitud de la universidad.

Creemos que así se obtiene un espacio público significativo sin la necesidad de desplazar o modificar el paso bajo nivel de la calle Lira. Este cuarto patio, de igual medida que los anteriores, nace de la prolongación de los corredores actuales de la universidad, aumentando así la intensidad de vida del Centro de Extensión, el cual queda como paso entre el campus, el nuevo proyecto y la ciudad.

Bajo el patio urbano se plantea un salónzócalo que complementa las actividades de extensión y de cierto modo, recrea las bodegas de albañilería existentes. Para ligar el patio con su zócalo se prolongan las columnas de la estructura subterránea, caracterizándola como un patio hipóstilo. El vacío
The new guiding plan seeks to create a unified space within the irregular block circumscribed by three streets: Alameda, Lira, and Quito. Like a great urban courtyard, the new buildings contribute to consolidating the university's presence in the center of

urbano del cuarto patio, toma distancia del tráfico de la Alameda y establece un vínculo visual con la planicie horizontal del faldeo del cerro Santa Lucía.

SEgundo elemento: edificios continuos / Conformando el perímetro edificado del patio urbano se proponen edificios de fachada continua de $35 \mathrm{~m}$ de altura. Una altura que relaciona este patio con las tres calles adyacentes. La expresión de las fachadas de estos edificios será de muros perforados, de modo que se integren a la rica variedad de este tipo de edificios que se encuentran en los alrededores. Estos edificios pertenecen a una primera escala del centro de la ciudad, donde la figura es el vacío y el fondo es el lleno. Se propone rematarlos con terrazasjardín que establezcan un nuevo vínculo con el cerro Santa Lucía y sus terrazas. La forma y dimensiones de estos edificios podrá variar en la medida que la universidad compre otros sitios adyacentes, manteniéndose, sin embargo, estable el patio.

TERCER ELEMENTO: TORRE DE CIEN METROS / El tercer elemento, en una tercera etapa consistirá en una torre esbelta que integra la sede universitaria a la escala actual del centro de la ciudad. Escala que incluye los grandes hitos verticales de cien o más metros. Al contrario de la escala mencionada en el punto anterior, en este caso la figura es el lleno y el fondo es el vacío. Un referente que reúne las dos escalas mencionadas es el Rockefeller Center de Nueva York, que presenta una torre en el paisaje urbano lejano y un vacío notable, lleno de vida en lo inmediato.

La condición de hito de esta torre propuesta se ve fortalecida por el quiebre en el trazado de la Alameda en el punto donde se ubica el proyecto. Esta torre establece una serie de calces, tanto en planta como en corte; con el edificio existente de la universidad, con el cerro Santa Lucía y con la ciudad. ARQ 

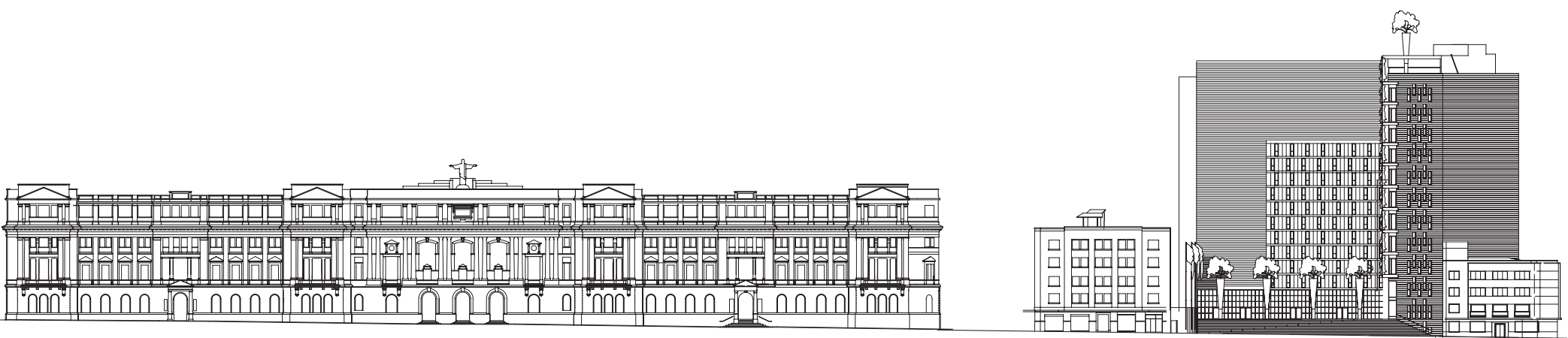

ELEVACIÓN NORTE E 1: 1250

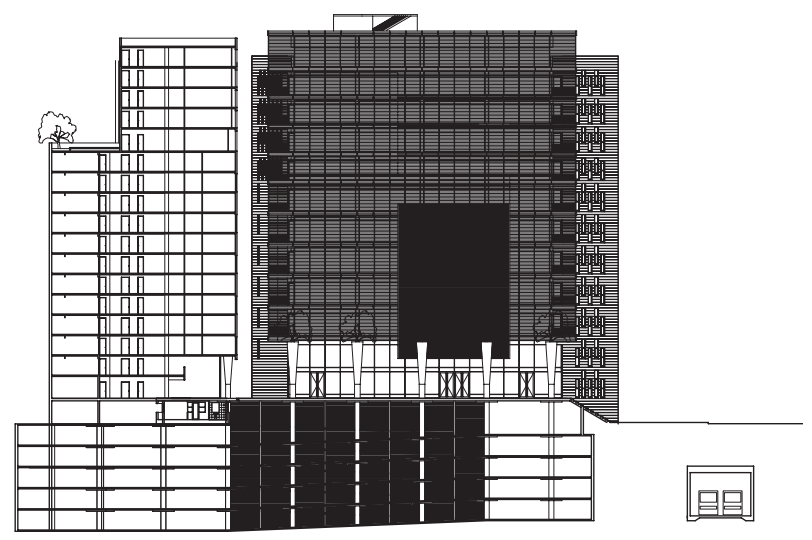

CORTE LONGITUDINAL AA

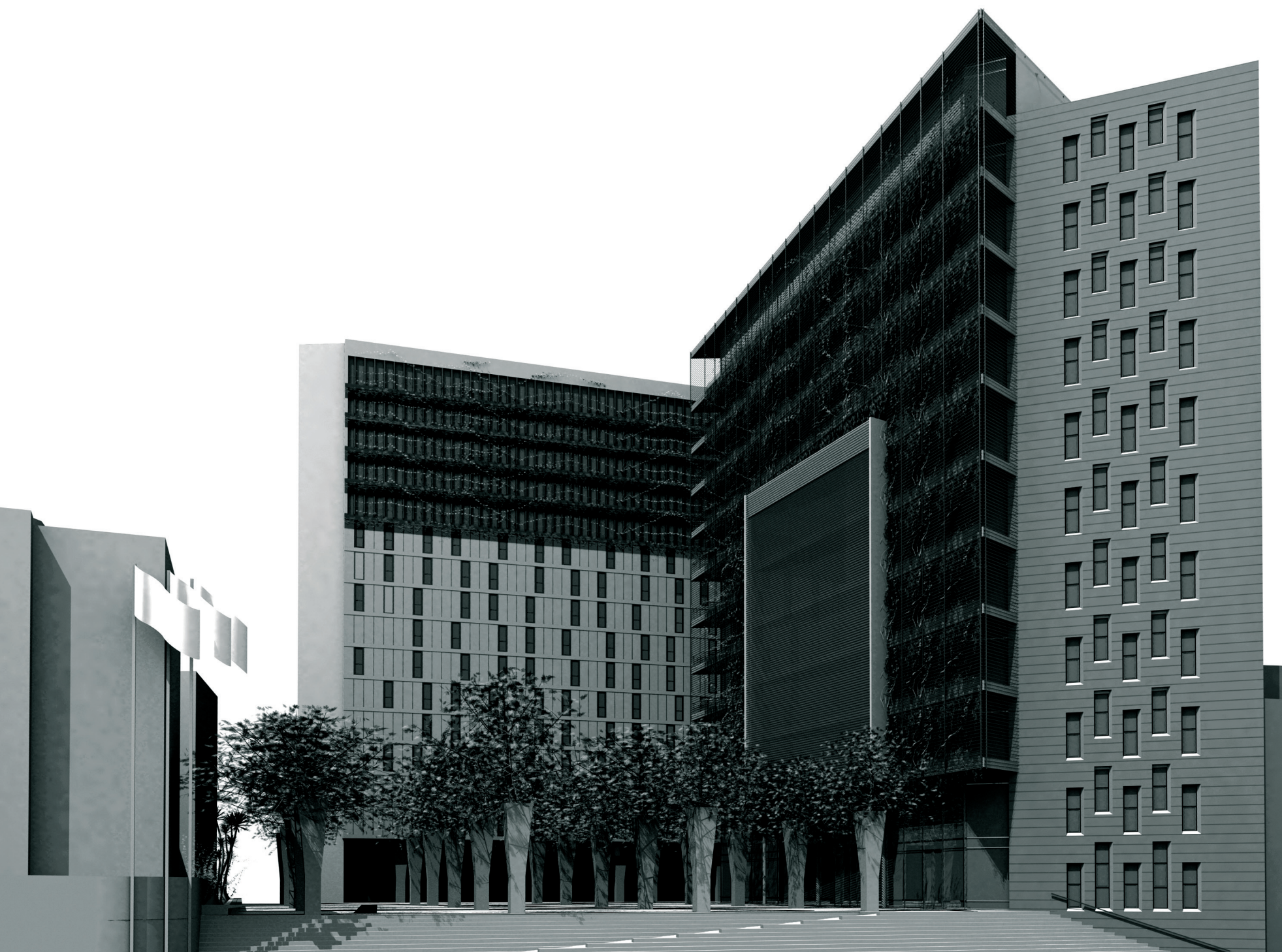




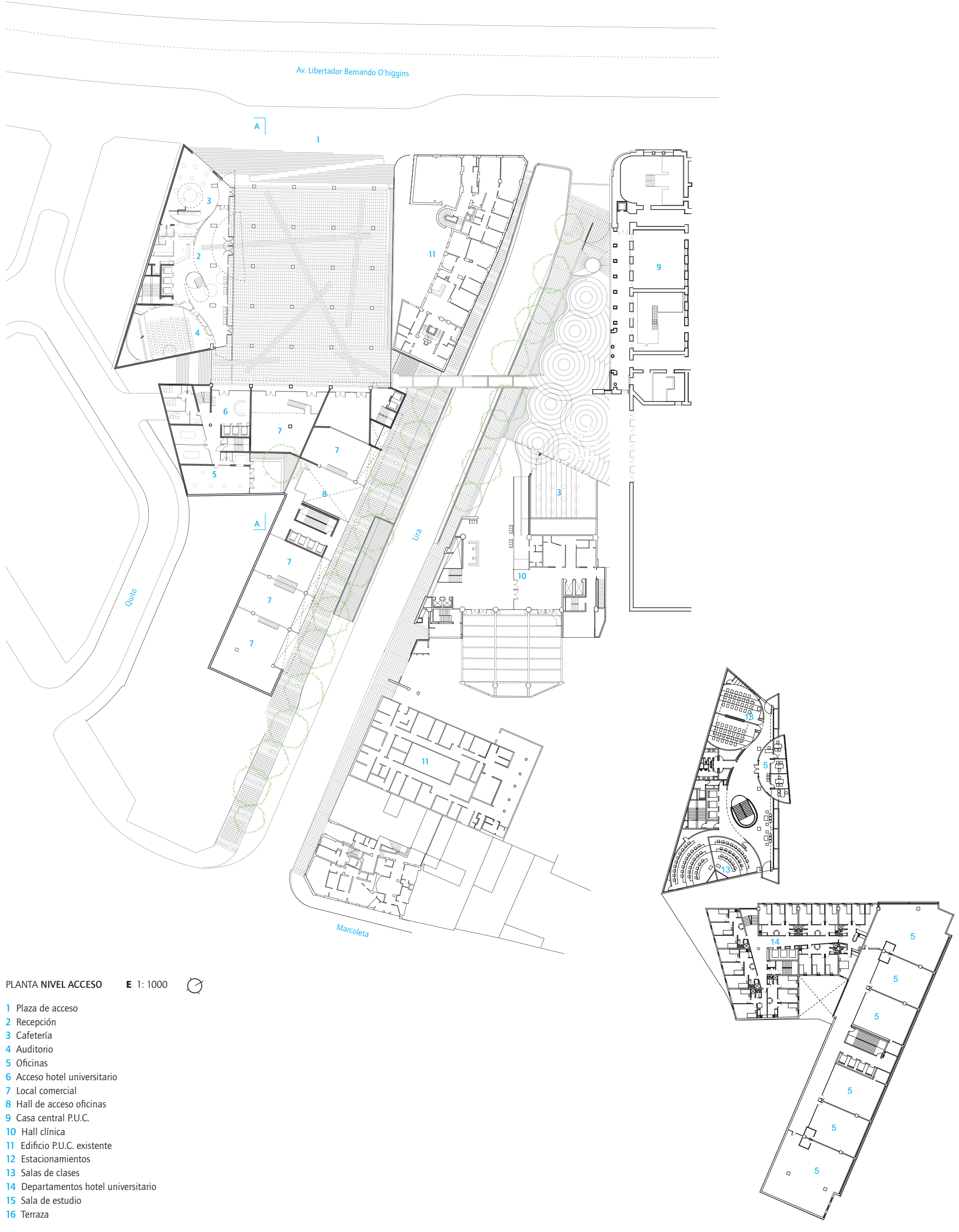



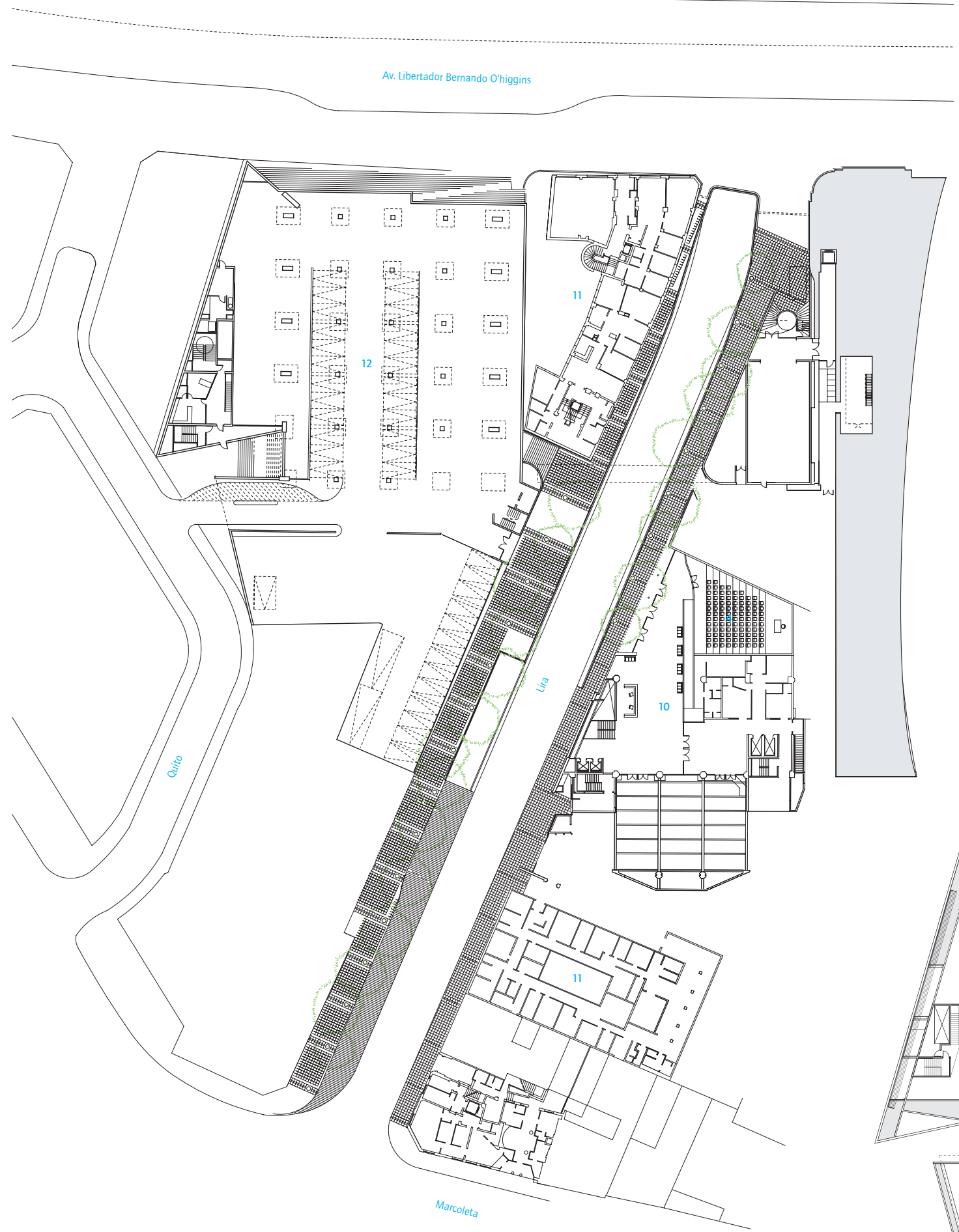

PLANTA NIVEL CALLE

\section{ALAMEDA, LIRA Y QUITO}

Arquitectos Juan Ignacio Baixas, Enrique del Río Colaboradores Felipe Dell `Orto, Pablo Bascur, Nicolás del Río, Manuel Sánchez

Ubicación Avda. Alameda Bernardo 0`higgins 414, Santiago, Chile

Cliente Dirección de Infraestructura, Pontificia Universidad Católica de Chile

Cálculo estructural Sergio Contreras y Asociados Construcción Mena y Ovalle

Materialidad hormigón armado

Presupuesto $15 \mathrm{UF} / \mathrm{m}^{2}$ (US\$530/m²) $1^{\text {era }}$ etapa Superficie terreno $5.000 \mathrm{~m}^{2}$

Superficie proyecto $16.645 \mathrm{~m}^{2}$ (recintos universitarios), $6.134 \mathrm{~m}^{2}$ (hotel universitario), $27.525 \mathrm{~m}^{2}$ (oficinas), $19.616 \mathrm{~m}^{2}$ (estacionamientos), 69.920 $\mathrm{m}^{2}$ (total)

Año proyecto 2001

Año construcción 2004 - 2008 (Desarrollo y construcción $1^{\text {era }}$ etapa), 2008 (Desarrollo $2^{\text {da }}$ etapa) Imágenes digitales Felipe Ramírez, Pablo Bascur

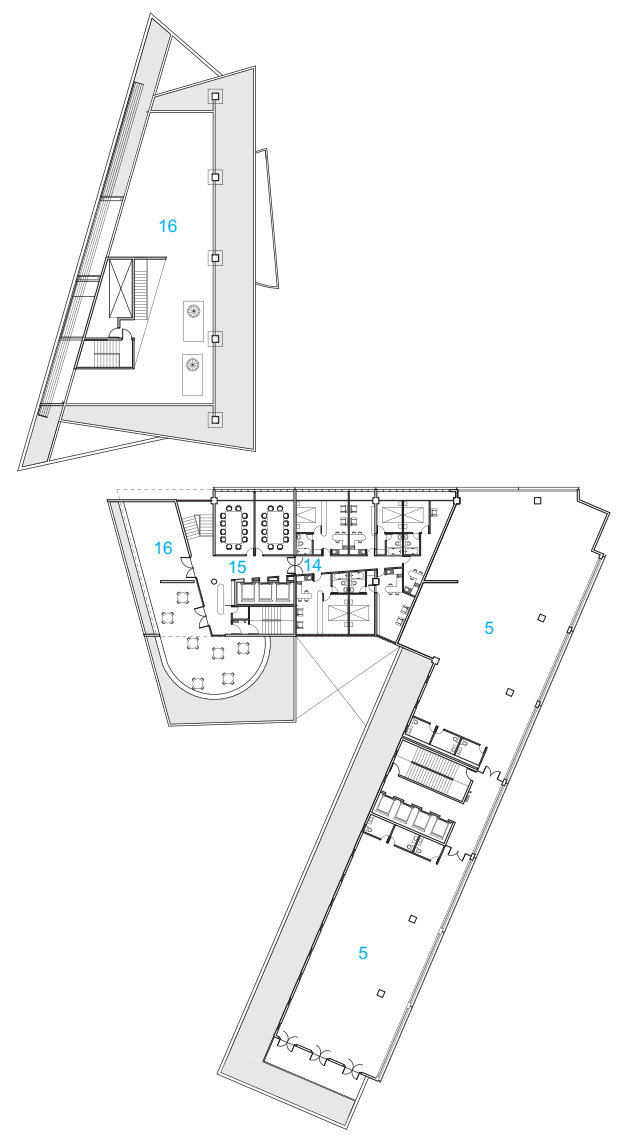

